\title{
Estudo preliminar das síndromes de polinização em um fragmento de Caatinga, PE, Brasil
}

\author{
Daniela Tábita de Lavor * \\ Aretuza Bezerra Brito Ramos \\ Faculdade de Ciências Humanas do Sertão Central \\ Rua Francisco Correa, 186, Bairro Santo Antônio, CEP 56000-000, Salgueiro - PE, Brasil \\ * Autor para correspondência \\ danielalavor@hotmail.com
}

Submetido em 30/11/2015

Aceito para publicação em 29/08/2016

\section{Resumo}

O objetivo do presente estudo foi identificar de forma preliminar as síndromes de polinização das espécies vegetais em um fragmento de Caatinga, no município de Serrita, Pernambuco, Brasil. Foi realizado um levantamento florístico durante o mês de março de 2014, em uma área de $900 \mathrm{~m}^{2}$. As espécies tiveram a morfologia e atributos florais caracterizados (cor e tamanho das flores, antese, presença de recursos florais, entre outros). Os conjuntos de parâmetros florais identificados foram utilizados para determinar as suas respectivas síndromes de polinização. A entomofilia foi o sistema de polinização mais frequente, ocorrendo em $76,12 \%$ das espécies, seguida pela ornitofilia (17,91\%) e quiropterofilia (5,97\%). A melitofilia prevaleceu em 52,24\% das espécies entomófilas. Os dados observados demonstram que as síndromes de polinização das espécies da área estudada seguem os mesmos padrões encontrados em outros ecossistemas brasileiros, onde se observa também a predominância da entomofilia/melitofilia como principal síndrome de polinização.

Palavras-chave: Entomofilia; Melitofilia; Transporte de pólen; Xerófitas

\section{Abstract}

Preliminary study of the pollination syndromes in a fragment of the Caatinga, in PE, Brazil. The aim of this study was to preliminarily identify the pollination syndromes of plant species in a fragment of the Caatinga, in the municipality of Serrita, Pernambuco, Brazil. A floristic survey was conducted during March 2014 in a $900 \mathrm{~m}^{2}$ area. The morphology and floral attributes of the species were characterized (e.g., color and size of flowers, anthesis, presence of floral resources). The sets of floral parameters identified were used to determine their respective pollination syndromes. Entomophily was the most frequent pollination system, occurring in $76.12 \%$ of the species, followed by ornithophily (17.91\%) and chiropterophily (5.97\%). Melittophily accounted for $52.24 \%$ of the entomophilous species. The observed data show that pollination syndromes of the species in the study area follow the same patterns found in other Brazilian ecosystems, where entomophily/melittophily is the main pollination syndrome.

Key words: Entomophily; Melittophily; Pollen transport; Xerophytes 


\section{Introdução}

A grande maioria das plantas possui adaptações em suas flores que atraem certos grupos de polinizadores, tais como disponibilidade e qualidade variável de néctar, odor, cor, formato, entre outros, o que pode agir restringindo o grupo visitante (BARBOSA, 1997). Nesse sentido, a partir da morfologia floral e dos recursos disponíveis na flor é possível identificar o polinizador, uma vez que essas características podem restringir ou orientar a acessibilidade de visitantes específicos aos recursos florais (SAKAI et al., 1998). Esse conjunto de características florais, incluindo as recompensas, pode ser usado para inferir os polinizadores, sendo então denominado por síndrome de polinização (FENSTER et al, 2004).

A ausência de um polinizador específico impede o estabelecimento de uma espécie de planta, assim sendo, os polinizadores podem atuar como um filtro do habitat. Portanto, estudos que avaliam a interação planta-polinizador são de grande importância, pois conhecendo a especificidade dessas interações é possível propor o manejo, a conservação e até mesmo a regeneração de comunidades vegetais (SARGENT; ACKERLY, 2008).

Diferentes autores (MCCALL; PRIMACK, 1992; HERRERA, 1996; 1998; ROZZI et al. 1997) têm questionado o valor preditivo das síndromes de polinização, pois identificaram que a maioria das espécies de plantas apresenta muitos polinizadores generalistas. Porém, a comunidade de polinizadores frequentemente converge com as síndromes de polinização, de modo que a abordagem por síndromes é um importante meio para compreender os mecanismos de diversificação das características florais (MOMOSE et al., 1998; DICKS et al., 2002; MUCHHALA, 2003; FENSTER et al., 2004; MACHADO; LOPES, 2004; STUURMAN et al., 2004), podendo os polinizadores ser agrupados em grupos funcionais (FENSTER et al., 2004).

O conceito de síndromes torna-se importante quando aplicado às comunidades, e constitui uma ferramenta para uma primeira abordagem nesse tipo de informação (FAEGRI; PIJL, 1976; DAFNI, 1982; PIJL, 1982).
Estudos utilizando o modelo de síndrome de polinização para identificação da diversidade de comunidade são frequentemente realizados, inclusive no bioma Caatinga (MACHADO; LOPES, 2004). Ressaltase que o conhecimento florístico e fitossociológico das espécies da Caatinga e o estudo das interações das plantas com os animais são fundamentais para a compreensão da estrutura e da dinâmica das comunidades e de seu processo de regeneração, constituindo importantes ferramentas para a conservação (DANIELI-SILVA et al., 2012).

Este bioma apresenta importância ecológica não somente pela diversidade biológica, com uma taxa significativa de espécies endêmicas, mas também porque essas espécies são adaptadas a um ambiente xérico (LEAL et al., 2005).

Desta forma, o objetivo deste estudo foi identificar as síndromes de polinização das espécies ocorrentes em um fragmento de Caatinga, em Serrita, Pernambuco, Brasil, uma vez que nesse município há uma Floresta Nacional em fase de implantação legal. Espera-se ainda poder subsidiar mais estudos de guildas de polinização e programas existentes de conservação.

\section{Material e Métodos}

\section{Área de estudo}

O estado de Pernambuco está localizado no centroleste da região Nordeste e ocupa uma área de 98.148,323 $\mathrm{km}^{2}$ (IBGE, 2010). Entre os municípios que compõe o estado, encontra-se Serrita (07056'00”S e 39¹7'45”W), com uma área de $1.664 \mathrm{~km}^{2}$, localizado na mesorregião do Sertão Central (Figura 1). Dista 544 km da capital Recife (IBGE, 2010).

Este estudo foi realizado na zona rural do município, no Sítio Urubu, a $18 \mathrm{~km}$ da sede municipal. A vegetação da área de estudo está sujeita à pressão antrópica oriunda de atividades como extração de madeira para lenha, estacas, carvão e ferramenta de uso doméstico.

A fitofisionomia presente no local é a Caatinga hiperxerófila em estágio sucessional secundário inicial, com solo marcadamente litólico. Destaca-se que apesar 
FIGURA 1: Mapa de localização do município de Serrita - PE, local de realização deste estudo.

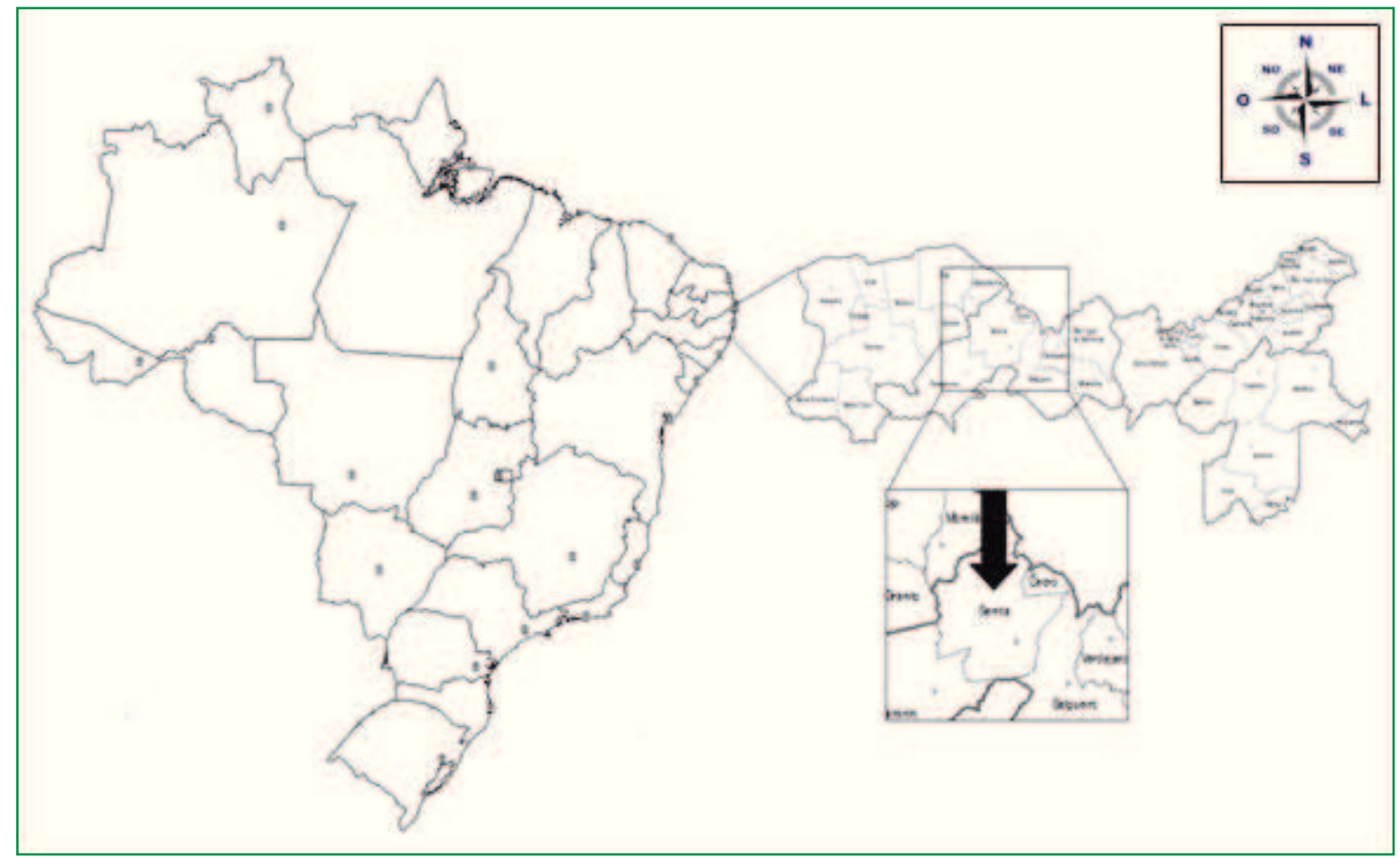

de a Caatinga ser um dos ambientes menos estudados do Brasil, com aproximadamente $40 \%$ de sua área ainda não amostrada e $80 \%$ subamostrada, são conhecidas, atualmente, 932 espécies de plantas, das quais 380 são endêmicas desse ambiente (LEAL et al., 2005).

\section{Estudo florístico e síndromes de polinização}

As coletas do material botânico foram realizadas durante o mês de março de 2014, sendo selecionadas três parcelas amostrais para realização do estudo. Cada parcela apresentava $10 \mathrm{~m}$ de comprimento por $30 \mathrm{~m}$ de largura, totalizando $900 \mathrm{~m}^{2}$ de área amostral. As parcelas foram dispostas na área de estudo no sentindo leste-oeste, com um intervalo de $10 \mathrm{~m}$ de uma para a outra.

As espécies presentes na área foram listadas inicialmente através do nome vernáculo e registro fotográfico. Posteriormente, foram identificadas com o auxílio de literatura especializada e por comparação com exemplares depositados no acervo do herbário UFPE, onde foram incorporados os materiais em estágio reprodutivo. Foi adotada a proposta de classificação de
APG III (2009), para as famílias, e os nomes dos autores das espécies foram abreviados segundo Brummitt e Powell (1992).

As espécies amostradas foram descritas conforme os atributos florais, sistema sexual e recompensa floral, assim como foram observados outros caracteres morfológicos, como a antese das flores, simetria e presença de odores (classificadas quanto à presença ou ausência de odores perceptíveis ao olfato humano, sendo os imperceptíveis classificados como ausentes).

Aquelas que se apresentavam em estágio reprodutivo no momento da amostragem tiveram seus dados coletados no mesmo período. Entretanto, aquelas que não possuíam flores tiveram os atributos florais descritos baseados em literatura pertinente.

As flores foram classificadas segundo sua morfologia, baseando-se em Souza et al. (2013), nas seguintes categorias: bilabiada, campanulada, hipocrateriforme, infundibuliforme e rotácea. Estas também foram dispostas em sete categorias de cores, considerando a cor predominante mais conspícua: branca, amarela, lilás, azul, vermelha (incluindo laranja), 
esverdeada (incluindo bege e creme) e rosa (claro e magenta), conforme Machado e Lopes (2003). Os tipos de simetrias considerados para este estudo foram analisados de acordo com Souza et al. (2013).

Com relação à antese foi considerado o período durante o qual a flor está disponível para a polinização. Destarte, foram utilizados dois intervalos: diurno (período com incidência solar) e noturno (sem incidência solar), tomando como base as informações constantes na literatura existente.

Cinco classes de recursos foram consideradas: pólen, néctar, óleo, resina e látex, baseadas em Faegri e Pijl (1979). No entanto, quando a flor apresentou mais de um recurso, estes foram contabilizados como recursos independentes.

As espécies foram classificadas também quanto à presença dos órgãos reprodutivos nas flores, sendo as plantas classificadas como monoicas e dioicas, e as flores como monoclinas ou diclinas, conforme Bawa (1980) e Gonçalves e Lorenzi (2011). Neste sentido, tais características (atributos florais, sistema sexual e recurso floral) embasaram a classificação quanto às síndromes de polinização predominantes, tomando como base também os estudos realizados por Faegri e Pijl (1976), Endress (1994) e Gonçalves e Lorenzi (2011).

Foram consideradas somente as síndromes de polinização bióticas, sendo estas a entomofilia, ornitofilia e a quiropterofilia. A entomofilia compreende a polinização realizada por insetos e como cada grupo da entomofauna tem suas particularidades, segregou-se a entomofilia em síndromes específicas, sendo estas a falenofilia (polinização por mariposas), psicofilia (borboletas), melitofilia (abelhas) e miofilia (moscas).

\section{Resultados}

\section{Composição florística}

$\mathrm{Na}$ área amostrada, foram encontradas 46 espécies distribuídas em 16 famílias botânicas (Tabela 1), sendo com maior representatividade a Fabaceae $(21,76 \%)$, a Cactaceae $(19,57 \%)$ e a Euphorbiaceae $(15,22 \%)$, concebendo um total de $56,53 \%$ das espécies levantadas.

Quanto ao hábito, entre as espécies amostradas houve predominância do estrato arbóreo $(43,48 \%)$, seguido do arbustivo $(21,74 \%)$, herbáceo $(15,21 \%)$, liana $(10,87 \%)$ e subarbusto $(8,70 \%)$.

TABELA 1: Lista florística das espécies encontradas na área de Caatinga Hiperxerófila amostrada em Serrita - PE.

\begin{tabular}{|c|c|c|c|c|c|c|c|}
\hline Família/Espécie & $\begin{array}{c}\text { Nome } \\
\text { Vernáculo }\end{array}$ & 总 & 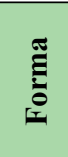 & 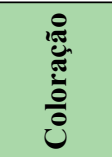 & 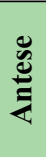 & 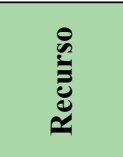 & 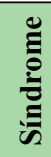 \\
\hline \multicolumn{8}{|l|}{ AMARANTHACEAE } \\
\hline Alternanthera tenella Colla & Quebra-panela & er & rot & bra & $\mathrm{d}$ & ne & me \\
\hline \multicolumn{8}{|l|}{ ANACARDIACEAE } \\
\hline Myracrodruon urundeuva Allemao & Aroeira & ar & cam & esv & $\mathrm{d}$ & po/ne/re & me \\
\hline Schinopsis brasiliensis Engl. & Baraúna & ar & cam & esv & $\mathrm{d}$ & $\mathrm{po} / \mathrm{ne}$ & me \\
\hline Spondias tuberosa Arruda & Umbuzeiro & ar & rot & bra & $\mathrm{d}$ & po/ne & me \\
\hline \multicolumn{8}{|l|}{ APOCYNACEAE } \\
\hline Aspidosperma pyrifolium Mart. & Pereiro & ar & hip & bra & $\mathrm{d}$ & ne/po/re & me \\
\hline \multicolumn{8}{|l|}{ BORAGINACEAE } \\
\hline Heliotropium indicum $\mathrm{L}$. & Crista-de-galo & er & hip & bra e lil & $\mathrm{d}$ & ne & me \\
\hline Varronia leucocephala (Moric.) J.S.Mill & Moleque-duro & $\mathrm{ab}$ & $\inf$ & bra & $\mathrm{d}$ & po/ne & me \\
\hline \multicolumn{8}{|l|}{ BROMELIACEAE } \\
\hline Bromelia laciniosa Mart. ex Schult. & Macambira & er & hip & $\operatorname{ros}$ & $\mathrm{d}$ & ne & or \\
\hline Neoglaziovia variegata (Arruda) Mez. & Caroá & er & $\mathrm{h}$ & ver & $\mathrm{d}$ & ne & or \\
\hline \multicolumn{8}{|l|}{ BURSERACEAE } \\
\hline Commiphora leptophloeos (Mart.) J. B. Gillett & Imburana-de-cambão & ar & hip & esv/ama & $\mathrm{d}$ & $\mathrm{po} / \mathrm{ne}$ & me \\
\hline
\end{tabular}




\section{CACTACEAE}

Arrojadoa rhodantha Britton \& Rose

Cereus jamacaru DC.

Harrisia adscendens (Gürke) Britton \& Rose

Melocactus bahiensis (Britton \& Rose) Werderm.

Melocactus zehntneri (Britton \& Rose) Luetzelb.

Pilosocereus pachycladus F.Ritter

Pilosocereus gounellei (F. A. C. Weber) Byles \&

G. D. Rowley

Tacinga inamoena (K.Schum.) N. P. Taylor \& Stuppy

Tacinga palmadora (Britton \& Rose) N. P. Taylor

CAPPARACEAE

Cynophalla flexuosa (L.) J.Presl

CLEOMACEAE

Tarenaya spinosa (Jacq.) Raf.

COMMELINACEAE

Commelina erecta L.

\section{CONVOLVULACEAE}

Ipomea asarifolia (Desr.) Roem. \& Schult.

Ipomea nil (L.) Roth

Ipomea sericophylla Meissn.

EUPHORBIACEAE

Cnidoscolus phyllacanthus (M. Arg.) Pax et K. Hoffm.

Cnidoscolus pubescens Pohl.

Cnidoscolus urens (L.) Arthur

Croton heliotropiifolius Kunth.

Croton sonderianus Mull. Arg.

Jatropha mollissima (Pohl) Baill.

Manihot glaziovii Mull. Arg.

\section{FABACEAE}

Amburana cearensis (Allemao) A.C.Sm.

Anadenanthera colubrina (Vell.) Brenan

Dioclea grandiflora Mart. ex Benth.

Mimosa tenuiflora (Willd.) Poir.

Piptadenia moniliformis Benth.

Piptadenia stipulacea (Benth.) Ducke

Poincianella pyramidalis (Tul.) L. P. Queiroz

Senna obtusifolia (L.) H. S. Irwin \& Barneby

Senna spectabilis (DC.) H.S.Irwin \& Barneby

MALVACEAE

Herissantia tiubae (K.Schum.) Brizicky

Melochia tomentosa $\mathrm{L}$.

PASSIFLORACEAE

Passiflora foetida $\mathrm{L}$.

RHAMNACEAE

Ziziphus joazeiro Mart.
Libidibia ferrea (Mart. ex Tul.) L. P. Queiroz

Rabo-de-raposa
Mandacaru
Rabo-de-raposa
Coroa-de-frade
Coroa-de-frade
Facheiro

\begin{tabular}{cccccc} 
ab & hip & ros & $\mathrm{d}$ & po/ne & $\mathrm{me} / \mathrm{ps} / \mathrm{or} / \mathrm{mi}$ \\
$\mathrm{ar}$ & hip & bra & $\mathrm{n}$ & ne & fa/qi \\
$\mathrm{ab}$ & hip & bra & $\mathrm{n}$ & ne & qi \\
$\mathrm{er}$ & hip & ros & $\mathrm{d}$ & ne & or \\
$\mathrm{er}$ & hip & ros & $\mathrm{d}$ & ne & or \\
$\mathrm{ab}$ & cam & esv & $\mathrm{n}$ & ne & $\mathrm{qi}$ \\
$\mathrm{ab}$ & cam & bra & $\mathrm{n}$ & $\mathrm{ne}$ & $\mathrm{me} / \mathrm{fa} / \mathrm{or}$ \\
$\mathrm{ab}$ & hip & ver & $\mathrm{d}$ & $\mathrm{ne}$ & $\mathrm{ps} / \mathrm{or}$ \\
$\mathrm{ab}$ & hip & ver & $\mathrm{d}$ & $\mathrm{ne}$ & $\mathrm{ps} / \mathrm{or}$ \\
\hline
\end{tabular}

Xique-xique

Quipá

Palmatória

Feijão-bravo

ar rot bra n ne

fa

Mussambê as rot bra $\mathrm{n}$ ne $\mathrm{me} / \mathrm{fa} / \mathrm{qi}$

$\begin{array}{ccccccc}\text { Salsa } & \text { li } & \text { cam } & \text { lil } & \text { d } & \text { ne } & \text { me } \\ \text { Jitirana-azul } & \text { li } & \text { cam } & \text { azu } & \text { d } & \text { po/ne } & \text { me } \\ \text { Jitirana-branca } & \text { li } & \text { cam } & \text { bra } & \text { d } & \text { po/ne } & \mathrm{me} / \mathrm{ps}\end{array}$

$\begin{array}{ccccccc}\text { Faveleira } & \text { ar } & \text { hip } & \text { bra } & \text { d } & \text { po/ne/re } & \text { me } \\ \text { Favela-mansa } & \text { ar } & \text { hip } & \text { bra } & \text { d } & \text { ne } & \text { me } \\ \text { Cansanção } & \text { ab } & \text { hip } & \text { bra } & \text { d } & \text { ne } & \mathrm{me} / \mathrm{ps} \\ \text { Quebra-faca } & \text { ar } & \text { rot } & \text { bra } & \text { d } & \text { po/ne } & \mathrm{me} \\ \text { Marmeleiro } & \text { ab } & \text { rot } & \text { bra } & \text { d } & \text { po/ne } & \mathrm{me} / \mathrm{ps} \\ \text { Pinhão-roxo } & \text { ab } & \text { cam } & \text { ver } & \text { d } & \text { po/ne/la } & \mathrm{me} / \mathrm{ps} / \mathrm{mi} / \mathrm{or} \\ \text { Maniçoba } & \text { ar } & \text { cam } & \text { esv e lil } & \mathrm{d} & \mathrm{po} / \mathrm{ne} & \mathrm{me}\end{array}$

Legenda: Hábito ( $\mathrm{ar}=$ árvore; $\mathrm{ab}=$ arbusto; as = subarbusto; er = erva; li = liana); Forma (bil = bilabiada; cam = campanulada; hip = hipocrateriforme; inf = infundibuliforme; rot = rotácea); Coloração (bra = branca; esv = esverdeada; ama = amarela; lil = lilás; azu = azul; ver = vermelha; ros = rosa); Antese $(\mathrm{d}=$ diurna; $\mathrm{n}=$ noturna); Recurso (po = pólen; ne = néctar; re = resina; la = látex); Síndrome de polinização $(\mathrm{me}=$ melitofilia, $\mathrm{fa}=$ falenofilia, $\mathrm{mi}=$ miofilia, or $=$ ornitofilia, $\mathrm{ps}=$ psicofilia, $\mathrm{qi}=$ quiropterofilia $)$. 


\section{Morfologia e atributos florais}

Flores rotácea e hipocrateriforme corresponderam a $35,72 \%$ cada uma, sendo estas as mais representativas entre as formas observadas, seguidas por campanulada, com $23,80 \%$, bilabiada $(2,38 \%)$ e infundibuliforme $(2,38 \%)$.

Foi observada uma maior proporção de flores claras (branca ou esverdeada), com 58,33\%, sendo as demais consideradas flores vistosas com periantos vermelhos, amarelos, lilases, rosas e azuis. Espécies com flores brancas foram as mais frequentes $(45,83 \%)$.

Flores actinomorfas foram encontradas na grande maioria das espécies, representando um total de $71,74 \%$, seguidas por zigomorfa $(15,21 \%)$ e assimétrica $(13,04 \%)$.

Quanto ao período de abertura da flor, prevaleceram aquelas que tinham antese diurna, com $86,96 \%$, e em relação ao odor presente nas flores, em $52,17 \%$ das espécies identificadas, este estava presente.
Foi registrada uma grande diversidade de tipos de recursos florais, incluindo resina e látex, no entanto o néctar foi o recurso mais frequente, com 61,43\% (Figura 2).

A frequência de espécies monoicas foi expressiva, visto que correspondeu a um total de $93,48 \%$ (desse total $81,40 \%$ são diclinas e 18,60\% são monoclinas).

\section{Síndromes de polinização}

A entomofilia foi o sistema de polinização mais frequente, ocorrendo em $76,12 \%$ das espécies estudadas, seguida pela ornitofilia $(17,91 \%)$ e quiropterofilia $(5,97 \%)$, conforme apresentado na Tabela 1 . Entre as espécies entomófilas, a melitofilia prevaleceu com $52,24 \%$ em relação às demais síndromes (Figura 3).

As famílias mais representativas em relação a espécies ornitófilas foram Bromeliaceae e Cactaceae. Espécies quiropterófilas foram encontradas em maior número na família Cactaceae, a melitofilia, por sua vez, esteve presente em pelo menos uma espécie de cada família, com exceção da Bromeliaceae, em que se registrou apenas a ornitofilia.

FIGURA 2: Recursos florais de espécies vegetais em área de Caatinga amostrada em Serrita - PE.

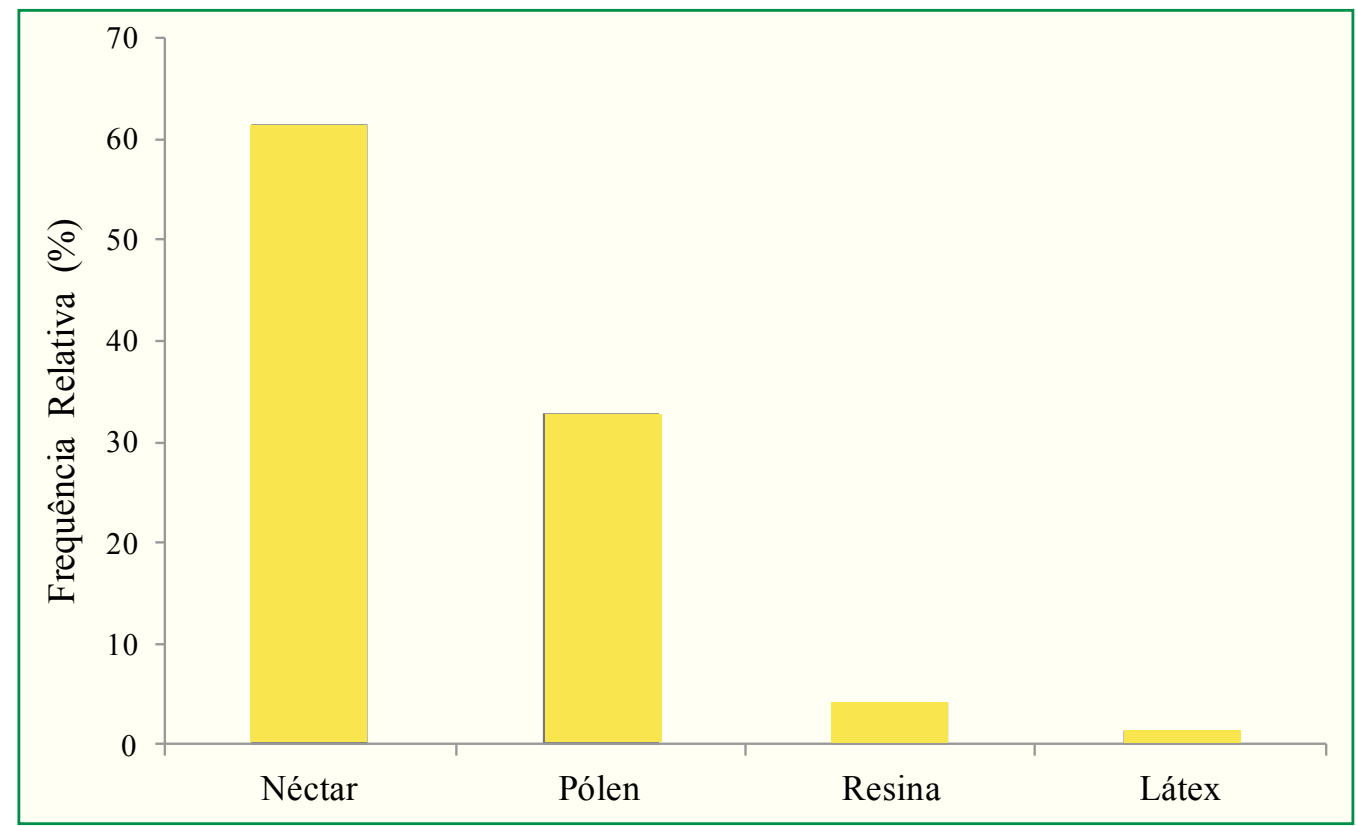


FIGURA 3: Síndromes de polinização encontradas em área de Caatinga amostrada em Serrita - PE.

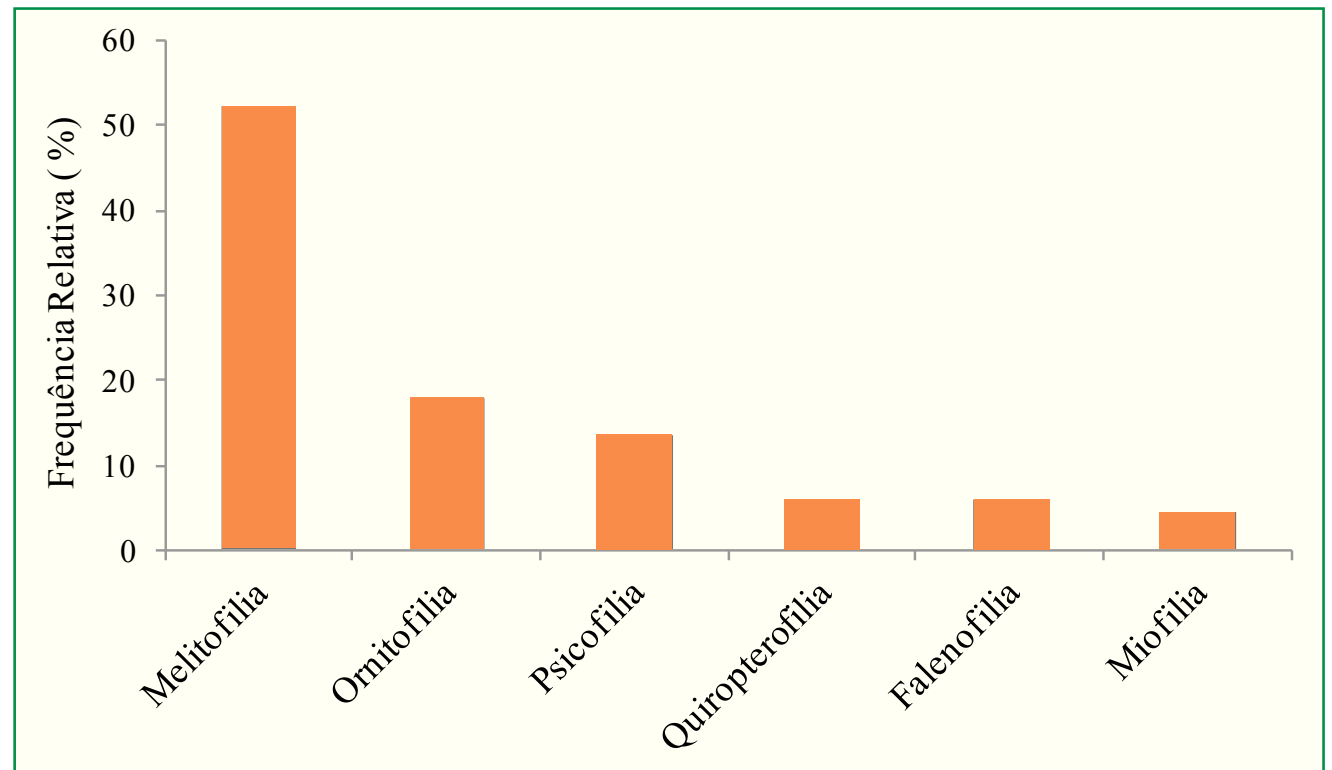

\section{Discussão}

O número de espécies e famílias encontradas está dentro da média dos levantamentos realizados no bioma Caatinga (BARBOSA et al., 2012). Contudo, os resultados obtidos quanto ao número de espécies e famílias foram inferiores aos de Lemos e Rodal (2002), Rodal et al. (2008b) e Ramalho et al. (2009), e superiores aos encontrados por Barbosa et al. (2012); Andrade et al. (2005) e Rodal et al. (2008a).

Os resultados obtidos corroboraram os de Giulietti et al. (2006), que, em um levantamento também realizado no bioma, indicaram Fabaceae como a família de maior representatividade, com 278 espécies registradas. Santos e Melo (2010) também apresentaram em seus resultados Fabaceae como a família que possuía o maior número de representantes, seguida de Cactaceae e Euphorbiaceae, sendo esses resultados semelhantes aos encontrados neste trabalho. Representantes dessas famílias apresentam-se notáveis em áreas de Caatinga, sendo observados também em outros trabalhos sobre composição florística (ANDRADE et al., 2009; OLIVEIRA et al., 2009; SOUZA; RODAL, 2010).

A apresentação da família Fabaceae como uma das mais representativas em resultados de muitos levantamentos florísticos realizados pode ser explicada pelo fato de ela estar incluída entre as principais famílias dos ecossistemas naturais brasileiros (SOUZA; LORENZI, 2008).

Vale salientar que entre as espécies identificadas neste levantamento florístico encontram-se a Aroeira (Myracrodruon urundeuva Allemao) e a Baraúna (Schinopsis brasiliensis Eng1.), reconhecidas pelo Ministério do Meio Ambiente como ameaçadas de extinção, apresentando alto risco de desaparecimento na natureza (MMA, 2008).

Todavia, deve-se levar em consideração o fato de que a região encontra-se no quarto ano consecutivo de estiagem, o que permite a observação em maior proporção das espécies com hábito arbóreo e arbustivo. Segundo Appezzato-da-Glória e Carmello-Guerreiro (2009), tais espécies apresentam estratégias de adaptação ao estresse hídrico, o que favoreceria a sua ocorrência nesse período.

Barbosa et al. (2012), em levantamento florístico realizado em uma área de Caatinga no município de Arcoverde-PE, identificaram o hábito arbóreo como predominante entre as espécies amostradas. Estudos realizados por Araújo et al. (2010) e Santos e Melo (2010) também apresentaram o estrato arbóreo como predominante, seguido pelo arbustivo. Não obstante, 
diferindo dos resultados obtidos no presente estudo, Ferreira (2011) identificou o hábito herbáceo com maior número de representantes em uma área de Caatinga remanescente.

Com relação ao formato da corola, é possível afirmar que há uma relação direta com o tipo de polinizador, uma vez que os dados obtidos neste estudo demonstraram que $73,33 \%$ das flores com formato hipocrateriforme apresentaram as síndromes de polinização ornitofilia e psicofilia. Os principais representantes dessas síndromes são respectivamente o beija-flor (Apodiforme) e a borboleta (Lepidoptera).

Os beija-flores são notáveis pelo bico fino e língua longa, que penetra na corola (geralmente tubulosa) das flores em busca do néctar; e as borboletas, por sua vez, possuem uma probóscide longa e fina, preferindo assim corolas hipocrateriformes, pois estas possuem um formato de tubo estreito que se expande abruptamente no ápice, sendo esta uma característica fundamental, já que as borboletas necessitam pousar sobre as flores para buscar o néctar (GONÇALVES; LORENZI, 2011).

Flores rotáceas, que estão entre as mais representativas neste estudo, apresentam tubo geralmente curto, com limbo amplo, de forma que a flor mantenhase mais aberta, expondo os verticilos reprodutivos (GONÇALVES; LORENZI, 2011), sendo possível a polinização por abelhas (melitofilia), que usam as estruturas acessórias como campo de pouso.

As flores hipocrateriformes também estão entre as mais representativas formas florais observadas, corroborando os resultados de Machado e Lopes (2003). Salienta-se que essas flores apresentam tubo estreito que se expande abruptamente no ápice (GONÇALVES; LORENZI, 2011), mas que podem ser visitadas por abelhas, como relatado por Oliveira et al. (2014), que identificaram em Harconia speciosa (Gomes) a polinização por Euglossini.

A predominância de flores claras neste estudo não corrobora os resultados de Machado e Lopes (2003), em estudo realizado no bioma Caatinga, onde houve uma maior concentração de flores vistosas. Ressalta-se que as autoras realizaram o trabalho no mesmo período hidrológico do presente estudo, mas em uma área de
Caatinga Hipoxerófita que, segundo Braga (2008), apresenta um período chuvoso superior ao da área aqui amostrada.

Nos trabalhos realizados na vegetação de Cerrado (SILBERBAUER-GOTTSBERGER; GOTTSBERGER, 1988), de florestas úmidas (MANTOVANI; MARTINS, 1988) e de Campo Sujo (BARBOSA, 1997) também houve o predomínio de cores claras. Conforme Faegri e Pijl (1976), Endress (1994) e Gonçalves e Lorenzi (2011) as flores de coloração clara estão associadas às síndromes de polinização denominadas falenofilia, psicofilia, melitofia, miofilia e quiropterofilia.

Momose et al. (1998) afirmam que as semelhanças de cores encontradas em ambientes diversos demonstram pouca significância entre esse atributo e os sistemas de polinização. Apesar de uma determinada cor não ser fortemente associada a um sistema de polinização específico, não se pode negar que alguns polinizadores visitem preferencialmente flores de determinadas cores (MACHADO; LOPES, 2003).

Faegri e Pijl (1979), Machado et al. (1997) e Machado e Lopes (2003) observaram espécies que possuem flores claras sendo visitadas por morcegos. No presente estudo, essa coloração está presente nas espécies de Cactaceae identificadas, que também apresentavam antese noturna e corola ampla, características relacionadas à quiropterofilia. $\mathrm{O}$ mesmo pode ocorrer na relação entre beija-flores e flores vermelhas/rosas, para a síndrome de ornitofilia.

A antese diurna prevaleceu nas flores amostradas e, conforme Faegri e Pijl (1979), é possível afirmar que o momento de abertura de uma flor está diretamente associado ao seu polinizador. Esses autores também afirmam que todas as flores que possuem antese noturna apresentam pelo menos um tipo de polinização que o animal que a realiza possui hábitos noturnos. Entre as espécies identificadas no presente estudo, é possível citar a espécie Cereus jamacaru DC. (Mandacaru), que possui antese noturna e tem como síndrome de polinização a falenofilia e quiropterofilia, como mencionado anteriormente.

Vale salientar que algumas espécies merecem destaque por apresentarem antese noturna de suas 
flores e durante o dia continuarem recebendo visitas de outros polinizadores. As espécies Pilosocereus gounellei (F. A. C. Weber) Byles \& G. D. Rowley (xiquexique) e Tarenaya spinosa (Jacq.) Raf. (mussambê) desenvolveram esse mecanismo, com o qual é possível atrair um maior número de polinizadores, já que as flores dessas espécies estão disponíveis para polinização nos dois períodos do dia. Assim esses fatos corroboram os estudos de Lucena (2009), quando afirma que para a espécie $P$. gounellei foram identificadas as seguintes síndromes: quiropterofilia, melitofilia, falenofilia e ornitofilia.

A sobreposição no uso dos recursos florais, tanto pelos visitantes diurnos quanto pelos noturnos, pode favorecer essas espécies, pois a ausência de um dos polinizadores em um período do dia pode ser compensada por outro, uma vez que o bioma Caatinga vem sofrendo fortes pressões decorrentes dos processos de isolamento e fragmentação da vegetação (LUCENA, 2009).

A espécie T. spinosa apresentou três tipos diferentes de síndromes de polinização (melitofilia, falenofilia e quiropterofilia). As flores apresentam características relacionadas principalmente à síndrome de quiropterofilia, tais como pétalas pouco vistosas, antese noturna, presença de odor e grande produção de néctar. No entanto, muitas espécies de abelhas nativas visitam suas flores durante o dia (MAIA-SILVA et al., 2012).

Em relação ao odor disponível nas flores, como na maioria das espécies ele estava presente, considerase que esse atributo leva os polinizadores a buscar por determinadas flores, uma vez que muitos destes não possuem uma boa visão para cores e guiam-se pelo olfato.

O néctar foi o recurso mais frequente, uma vez que esse recurso é utilizado tanto pela entomofauna como pelas espécies ornitófilas e quiropterófilas. Machado e Lopes (2003) também identificaram o néctar como principal recurso floral das espécies identificadas por elas em uma área de Caatinga.

Com relação ao sistema sexual verificou-se uma maior frequência de espécies monoicas, diferentemente de Machado e Lopes (2003), que encontraram em sua pesquisa apenas $9,7 \%$ de espécie que apresentam essa estratégia reprodutiva.

A ornitofilia apresentou frequência relativamente alta quando comparado ao encontrado por Quirino (2006), na Caatinga, e Araújo et al. (2009), em área de Mata Atlântica. Todavia, os resultados obtidos para a quiropterofilia foram inferiores aos encontrados por Machado e Lopes (2003).

A melitofilia foi a síndrome mais representativa na área de Caatinga estudada, resultado semelhante ao encontrado em outras comunidades por Bawa et al. (1985) em floresta úmida, Quirino (2006) na Caatinga, Silberbauer-Gottsberger e Gottsberger (1988) no Cerrado, e Kang e Bawa (2003) na floresta seca. Isso vem a confirmar que a polinização por entomofilia, em especial a melitofilia, é representativa em vários ambientes estudados (CARA, 2006).

As abelhas sociais são os polinizadores mais versáteis e ativos, que obtêm recursos para si e para a prole em plantas com diferentes atributos florais (FAEGRI; PIJL, 1976). Algumas abelhas são capazes de vibrar anteras para a retirada de pólen em flores com deiscência poricida (BUCHMANN, 1983), como descrito por Maia-Silva et al. (2012) e Borges (2010) para espécies de Senna, ocorrentes no fragmento de Caatinga estudado.

No presente estudo, também foi registrada a presença da abelha Trigona spinipes (Fabricius, 1793), popularmente conhecida por arapuá, nas flores das espécies $P$. foetida (maracujá-do-mato), A. pyrifolium (pereiro), S. tuberosa (umbuzeiro) e $P$. gounellei (xique-xique). Esse tipo de abelha é conhecido por seu comportamento oportunista e generalista. Durante o período seco, somente algumas espécies de colônias perenes e alguns grupos de abelhas solitárias de maior porte mantêm suas atividades de forrageio, entre estas encontra-se a T. spinipes (ZANELA; MARTINS, 2003).

Deste modo, segundo Maia-Silva et al. (2012), essa espécie pode atuar como polinizadora, devido ao período de floração de algumas espécies de plantas acontecerem na estação de seca na Caatinga, como, por exemplo, o umbuzeiro e o maracujá-do-mato, que florescem nessa 
estação. Não obstante, Kiill et al. (2012) observaram que essas abelhas, durante o forrageio, muitas vezes dilaceravam as tépalas internas e os estames e, em alguns casos, cortavam o estigma da flor, sendo esse comportamento prejudicial à polinização, pois além de danificar as estruturas reprodutivas, deixa as flores menos atrativas.

De modo geral, um dos fatores que levam ao elevado índice da síndrome melitofilia é que as abelhas necessitam diretamente de plantas com flores para obter recursos alimentares, além de outros recursos utilizados na construção das colmeias. Existe uma variedade de especializações tanto por parte das abelhas como por parte das plantas, que resultam em uma complexa cadeia de inter-relações (ZANELA; MARTINS, 2003).

Os sistemas de polinização das espécies estudadas demonstram que, apesar das restrições climáticas da Caatinga, há uma diversificação no conjunto de características morfológicas e de recursos florais, que possibilita uma heterogeneidade de polinizadores para a região estudada.

Esses dados são importantes para aprimorar o conhecimento das interações existentes entre plantas e animais da Caatinga, sendo essas relações consideradas fundamentais para a compreensão da estrutura e da dinâmica das comunidades, constituindo, assim, importantes ferramentas para a conservação do bioma. Dessa forma, o presente estudo dá subsídios para experimentos futuros sobre guildas de polinização, principalmente em áreas de Caatinga Hiperxerófila.

\section{Referências}

ANDRADE, L. A.; PEREIRA, I. M.; LEITE, U. T.; BARBOSA, M. R. V. Análise da cobertura de duas fitofisionomias de caatinga, com diferentes históricos de uso, no município de São João do Cariri, estado da Paraíba. Cerne, Lavras, v. 11, n. 3, p. 253-262, 2005.

ANDRADE, M. V. M. de.; ANDRADE, A. P. de.; SILVA, D. S. da.; BRUNO, R. de. L. A.; GUEDES, D. S. Levantamento florístico e estrutura fitossociológica do estrato herbáceo e subarbustivo em áreas de caatinga no Cariri paraibano. Revista Caatinga, Mossoró, v. 22, n. 1, p. 229-237, 2009.

APPEZZATO-DA-GLÓRIA, B.; CARMELLO-GUERREIRO, S. M. Anatomia vegetal. 2 ed. Viçosa: Editora UFV, 2009. 305 p.

APG III. An update of the Angiosperm Phylogeny Group classification for the orders and families of flowering plants: APG
III. Botanical Journal of the Linnean Society, London, v. 161, p. 105-121, 2009.

ARAÚJO, J. L. O.; QUIRINO, Z. G. M.; NETO, P. C. G.; ARAÚJO, A. C. Síndromes de polinização ocorrentes em uma área de Mata Atlântica, Paraíba, Brasil. Biotemas, Florianópolis, v. 22, n. 4, p. 83-94, 2009.

ARAUJO, K. D.; PARENTE, H. N.; ÉDER-SILVA, E.; RAMALHO, C. I.; DANTAS, R. T.; ANDRADE, A. P.; SILVA, D. S. Levantamento florístico do estrato arbustivo-arbóreo em áreas contíguas de Caatinga no Cariri Paraibano. Revista Caatinga, Mossoró, v. 23, n. 1, p. 63-70, 2010.

BARBOSA, A. A. Biologia reprodutiva de uma comunidade de Campo Sujo, Uberlândia-MG. 1997. 180 f. Tese (Doutorado em Biologia Vegetal) - Universidade Estadual de Campinas, Campinas. 1997.

BARBOSA, M. D.; MARANGON, L. C.; FELICIANO, A. L. P.; FREIRE, F. J.; DUARTE, G. M. T. Florística e fitossociologia de espécies arbóreas e arbustivas em uma área de caatinga em Arcoverde, PE, Brasil. Revista Árvore, Viçosa, v. 36, n. 5, p. 851858, 2012.

BAWA, K. S. Evolution of dioecy in flowering plants. Annual Review of Ecology and Systematics, Palo Alto, v. 11, p. 15-39, 1980.

BAWA, K. S.; PERRY, D. R.; BEACH, J. H. Reproductive biology of tropical lowland rain forest trees. I. Sexual systems and incompatibility mechanisms. American Journal of Botany, Saint Louis, v. 72, n. 3, p. 331-343, 1985.

BORGES, L. A. A. P. Biologia reprodutiva de espécies lenhosas de Leguminosae na Caatinga. 2010. 114 f. Tese (Doutorado em Biologia Vegetal) - Universidade Federal de Pernambuco, Recife. 2010.

BRAGA, D. V. V. Áreas degradadas do bioma Caatinga na região de Xingó, Brasil: processo de formação $\mathrm{x}$ recuperação ambiental. 2008. 181 f. Dissertação (Mestrado em Gestão e Políticas Ambientais) - Universidade Federal de Pernambuco, Recife. 2008.

BRUMMITT, R. K.; POWELL, C. E. Authors of plant names. Canterbury: Whiststable Litho Ltds. 1992. 732 p.

BUCHMANN, S. L. Buzz pollination in angiosperms. In: JONES, C. E.; LITTER, R. J. (Ed.). Handbook of experimental pollination biology. New York: Van Nostrand \& Reinhold. 1983. p. 73-113.

CARA, P. A. A. Efeito de borda sobre a fenologia, as Síndromes de Polinização e a dispersão de sementes de uma comunidade arbórea na Floresta Atlântica ao norte do Rio São Francisco. 2006. 100 f. Tese (Doutorado em Biologia Vegetal) - Universidade Federal de Pernambuco, Recife. 2006.

DAFNI, A. Pollination ecology: a practical approach. Oxford, IRL Press. 1982. $250 \mathrm{p}$.

DANIELI-SILVA, A.; SOUZA, J. M. T. de; DONATTI, A. J.; CAMPOS, R. P.; VICENTE-SILVA, J.; FREITAS, L.; VARASSIN, I. G. Do pollination syndromes cause modularity and predict interactions in a pollination network in tropical high-altitude grasslands? Oikos, v. 121, p. 35-43, 2012.

DICKS, L. V.; CORBET, S.A; PYWELL, R.F. Compartmentalization in plant-insect flower visitor webs. Journal of Animal Ecology, London, v. 71, p. 32-43, 2002.

ENDRESS, P. K. Diversity and evolutionary biology of tropical flowers. Cambridge: Cambridge University Press, 1994. 407 p. 
FAEGRI, K.; PIJL, L. The principles of pollination ecology. Oxford: Pergamon Press, 1976. 291 p.

FENSTER, C. B.; ARMBRUSTER, W. S.; WILSON, P.; DUDASH, M.; THOMPSON, D. Pollination syndromes and floral specialization. Annual Review of Ecology, Evolution and Systematics, Palo Alto, v. 35, p. 375-403, 2004.

FERREIRA, E. V. R. Composição florística, estrutura da comunidade e síndrome de dispersão de sementes de um remanescente de Caatinga em Poço Verde - Sergipe. 2011. $81 \mathrm{f}$. Dissertação (Mestrado em Ecologia da Conservação) - Universidade Federal de Sergipe, São Cristóvão. 2011.

GIUlliETI, A. M.; CONCEICAO, A.; QUEIROZ, L. P. Diversidade caracterização das fanerógamas do semi-árido brasileiro. Recife: Associação Plantas do Nordeste, 2006. 488 p.

GONÇALVES, E. D.; LORENZI, H. Morfologia vegetal: organografia e dicionário ilustrado de morfologia das plantas vasculares. 2. ed. São Paulo: Instituto Plantarum de Estudos da Flora, 2011. 512 p.

HERRERA, C. M. Floral traits and adaptation to insect pollinators: a devil's advocate approach. In: LLOYD, D. G.; BARRETT, S. C. H. (Ed.). Floral Biology. New York: Chapman \& Hall. 1996. p. 65-87.

HERRERA, J. Pollination relationships in southeastern Spanish Mediterranean shrublands. Journal of Ecology, London, v. 76, p. 274-287, 1998.

IBGE - Instituto Brasileiro de Geografia e Estatística. 2010. Disponível em <http: www.ibge.gov.br/home/>. Acesso em: 18 setembro 2014.

KANG, H.; BAWA, K. S. Effects of successional status, habit, sexual systems, and pollinators on flowering patterns in tropical rain forest trees. American Journal of Botany, Saint Louis, v. 90, p. $865-876,2003$

KIILL, L. H. P.; SANTOS, A. P. B.; MARTINS, C. T. V. D.; SILVA, N. B. G.; SILVA, T. A. Ecologia da polinização da cactácea Arrojadoa rhodantha em caatinga hiperxerófila. Sitientibus - Série Ciências Biológicas, Feira de Santana, v. 12, n. 2, p. 303-312, 2012.

LEAL, I. R.; SILVA, J. M. C.; TABARELLI, M.; LACHER JR., T. Mudando o curso da conservação da biodiversidade na Caatinga do nordeste do Brasil. Megadiversidade, Belo Horizonte, v. 1, n. 1, p. 139-146, 2005.

LEMOS J. R.; RODAL, M. J. N. Fitossociologia do componente lenhoso de um trecho da vegetação de caatinga no Parque Nacional Serra da Capivara, Piaú, Brasil. Acta Botanica Brasilica, Feira de Santana, v. 16, n. 1, p. 23-42, 2002.

LUCENA, E. A. R. M. Fenologia, biologia da polinização e da reprodução de Pilosocereus Byles \& Rowley (Cactaceae) no Nordeste do Brasil. 2009. 154 f. Tese (Doutorado em Biologia Vegetal) - Universidade Federal de Pernambuco, Recife. 2009.

MACHADO, I. C.; BARROS, L. M.; SAMPAIO, E. V. S. B. Phenology of caatinga species

at Serra Talhada, PE, Northeastern Brazil. Biotropica. v. 29, p. 5768, 1997.

MACHADO, I. C.; LOPES, A. V. Recursos florais e sistemas de polinização e sexuais na Caatinga. In: LEAL, I. R.; TABARELLI, M.; SILVA, J. M. C. (Ed.). Ecologia e conservação da Caatinga. Recife: Editora Universitária da UFPE, 2003. p. 515-563.
MACHADO, I. C.; LOPES, A. V. Floral traits and pollination systems in the Caatinga, a Brazilian tropical dry forest. Annals of Botany, London, v. 94, n. 3, p. 365-376, 2004.

MAIA-SILVA, C.; SILVA, C. I.; HRNCIR, M.; QUEIROZ, R. T.; IMPERATRIZ-FONSECA, V. L. Guia de plantas: visitadas por abelhas na Caatinga. Fortaleza: Editora Fundação Brasil Cidadão, 2012. 99 p.

MANTOVANI, W.; MARTINS, F. R. Variações fenológicas das espécies do Cerrado da Reserva Biológica de Mogi Guaçu, estado de São Paulo. Revista Brasileira de Botânica, São Paulo, v. 11, p. 101-112, 1988.

MCCALL, C.; PRIMACK, R. B. Influence of flower characteristics, weather, time of day, and season on insect visitation rates in three plant communities. American Journal of Botany, Saint Louis, v. 79, p. 434-442, 1992.

MMA - MINISTÉRIO DO MEIO AMBIENTE. Instrução Normativa no 06, de 23 de setembro de 2008. Brasília: Diário Oficial da União.

MOMOSE, K.; YUMOTO, T.; NAGAMITSU, T.; KATO, M.; NAGAMASU, H.; SAKAI, S.; HARRISON, R. D.; ITIOKA, T.; HAMID, A.; INOUE, T. Pollination biology in a lowland dipterocarp forest in Sarawak, Malaysia. I. Characteristics of the plant-pollinator community in a lowland dipterocarp forest. American Journal of Botany, Saint Louis, v. 85, p. 1477-1501, 1998.

MUCHHALA, N. Exploring the boundary between pollination syndromes: bats and hummingbirds as pollinators of Burmeistera cyclostigmata and B. tenuiflora (Campanulaceae). Oecologia, Heidelberg, v. 134, p. 373-380, 2003.

OLIVEIRA, P. T. B. de.; TROVÃO, D. M. de B. M.; CARVALHO, E. C. D. de.; SOUZA, B. C. de.; FERREIRA. L. M. R. Florística e fitossociologia de quatro remanescentes vegetacionais em áreas de Serra no Cariri Paraibano. Revista Caatinga, Mossoró, v. 22, n. 4, p.169-178, 2009.

OLIVEIRA, R.; SCHLINDWEIN, C.; PINTO, E.; DUARTE JÚNIOR, J. A.; MARTINS, C.; ZANELLA, F. Diagnóstico e manejo dos polinizadores da mangabeira em Pernambuco e Paraíba: conservando polinizadores para produzir mangabas (Hancornia speciosa, Apocynaceae). In: YAMAMOTO, M.; OLIVEIRA, P. E.; GAGLIANONE, M. C. (Org.). Uso sustentável e restauração da diversidade dos polinizadores autóctones na agricultura e nos ecossistemas relacionados: planos de manejo. Vol. 1. Rio de Janeiro: Funbio, 2014. p. 79-96.

PIJL, L. van der. Principles of dispersal in higher plants. New York: Springer-Verlag, 1982. 214 p.

QUIRINO, Z. G. M. Fenologia, síndromes de polinização e dispersão e recursos florais de uma comunidade de Caatinga no Cariri paraibano. 2006. 164 f. Tese (Doutorado em Biologia Vegetal) - Universidade Federal de Pernambuco, Recife. 2006.

RAMALHO, C. I.; PEREIRA, A. A.; PESSOA, F. L.; VIEIRA, L. A.; BORGES, M. P. Flora arbóreo-arbustiva em áreas de Caatinga no Semiárido Baiano, Brasil. Revista Caatinga, Mossoró, v. 22, n. 3, p. 182-190, 2009.

RODAL, M. J. N.; COSTA, K. C. C.; SILVA, A. C. B. Estrutura da vegetação caducifólia espinhosa (Caatinga) de uma área do sertão central de Pernambuco. Hoehnea, São Paulo, v. 35, n. 2, p. 209217, 2008a. 
RODAL, M. J. N; MARTINS, F. R.; SAMPAIO, E. V. S. B. Levantamento quantitativo das plantas lenhosas em trechos de vegetação de caatinga em Pernambuco. Revista Caatinga, Mossoró, v. 21, n. 3, p. 192-205, 2008 b.

ROZZI, R.; ARROYO, M. K.; ARMESTO, J. J. Ecological factors affecting gene flow between populations of Anarthrophyllum cumingii (Papilionaceae) growing on equatorial-and polar-facing slopes in the Andes of Central Chile. Plant Ecology, Dordrecht, v. 132, p. 171-179, 1997.

SAKAI, Y.; KOLLER, A.; RANGELL, L. K.; KELLER, G. A.; SUBRAMANI, S. Peroxisome degradation by microautophagy in Pichia pastoris: identification of specific steps and morphological intermediates. Journal of Cell Biology, New York, 141, p. 625636, 1998.

SANTOS, A. C. J.; MELO, J. I. M. Flora vascular de uma área de Caatinga no estado da Paraíba - Nordeste do brasil. Revista Caatinga, Mossoró, v. 23, n. 2, p. 32-40, 2010.

SARGENT, R. D.; ACKERLY, D. D. Plant-pollinator interactions and the assembly of plant communities. Trends in Ecology \& Evolution, Amsterdam, v. 23, n. 3, p. 123-130, 2008.

SILBERBAUER-GOTTSBERGER, I.; GOTTSBERGER, G. A polinização de plantas do Cerrado. Revista Brasileira de Biologia, São Carlos, v. 48, n. 4, p. 651-663, 1988.
SOUZA, J. A. N.; RODAL, M. J. N. Levantamento florístico em trecho de vegetação ripária de Caatinga no Rio Pajeú, Floresta, Pernambuco, Brasil. Revista Caatinga, Mossoró, v. 23, n. 4, p. 54$62,2010$.

SOUZA, V. C.; FLORES, T. B.; LORENZI, H. Introdução à botânica: morfologia. São Paulo: Instituto Plantarum de Estudos da Flora, 2013. 222 p.

SOUZA, V. C.; LORENZI, H. Botânica sistemática: guia ilustrado para identificação das famílias de Fanerógamas nativas e exóticas no Brasil, baseado em APG II. 2. ed. Nova Odessa: Instituto Plantarum, 2008. 768 p.

STUURMAN, J.; HOBALLAH, M. E.; BROGER, L.; MOORE, J.; BASTEN, C.; KUHLEMEIER, C. Dissection of floral pollination syndromes in Petunia. Genetics, Pittsburgh, v. 168, p. 1585-1599, 2004.

ZANELLA, F. C. V.; MARTINS. C. F. Abelhas da caatinga: biogeografia, ecologia e conservação. In: LEAL, I. R.; TABARELLI, M.; SILVA, J. M. C. (Ed.). Ecologia e conservação da Caatinga. Recife: Editora Universitária da UFPE, 2003. p. 75-134. 